\title{
Profile of smokers and the role of dentists in tobacco use cessation: a cross-sectional study in southern Brazil
}

\author{
Carolina Dummel $^{\mathrm{a}}$, Sílvia Ataide Pithan ${ }^{\mathrm{b}}$, Ângela Isabel dos Santos Dullius ${ }^{\mathrm{c}}$
}

\begin{abstract}
OBJECTIVE: The aim of this study was to investigate the profile of smokers in a dental school in southern Brazil and their views about the role of dentists in tobacco use cessation.

METHODS: A cross-sectional study was carried out with patients of a dental school, who answered a face-to-face interview. Smokers also took the Fagerström Test for Nicotine Dependence. Data was analysed using descriptive statistics and Chi Square test with a significance level of $5 \%$.

Results: The sample consisted of 442 patients, and 93 patients (21.04\%) were smokers. The lower the level of schooling the higher the frequency of smokers $(p=0.026)$, and the frequency of nonsmokers was associated with higher income $(p=0.021)$. Regarding the role of dentists in smoking cessation, $97.8 \%$ of smokers believe that the dentist should provide information and advice, but $36.6 \%$ did not receive any orientation from dentists.

CONCLUSION: The study had found a higher frequency of smokers among men and an association between smoking and schooling as well as smoking and income. The majority of smokers would like to quit smoking and had tried at least once to stop. The sample believes that dentists should give information and advice about smoking cessation.
\end{abstract}

Key words: Tobacco; Tobacco use cessation; Nicotine; Health profile; Dentists

\section{Perfil de pacientes fumantes e o papel do cirurgião-dentista na cesssação: estudo transversal no sul do Brasil}

\section{RESUMO}

OBJETIVO: O objetivo deste estudo foi avaliar o perfil dos pacientes fumantes de um curso de Odontologia no sul do Brasil e sua opinião sobre o papel do cirurgião-dentista na cessação do tabagismo.

METODOLOGIA: Estudo transversal analítico, onde os dados foram coletados por meio de uma entrevista contendo questões fechadas e abertas. Os pacientes fumantes também responderam o Teste de Dependência à Nicotina de Fagerström. Os dados foram analisados por meio de estatística descritiva e do teste Qui-quadrado ao nível de significância de $5 \%$.

RESULTADOS: A amostra compreendeu 442 pacientes, sendo que $93(21,04 \%)$ eram fumantes. Verificou-se associação significativa entre fumo, escolaridade e renda, sendo que quanto menor a escolaridade, maior a frequência de fumantes $(p=0,026)$, e a frequência de não fumantes esteve associada a uma maior renda $(p=0,021)$. Em relação ao papel do cirurgião-dentista na cessação do tabagismo, $97,8 \%$ dos fumantes acredita que este deve dar orientações sobre os danos provocados pelo cigarro, mas $36,6 \%$ não receberam informações ou conselhos do dentista.

CONCLUSÃO: O estudo encontrou alta frequência de fumantes entre os homens e associação entre tabagismo, escolaridade e renda. A maioria dos fumantes gostaria de parar de fumar e tentou pelo menos uma vez. A maior parte da amostra acredita que o cirurgião-dentista deve fornecer informações e aconselhamento sobre a cessação do tabagismo.

Palavras-chave: Tabaco; Abandono do hábito de fumar; Nicotina; Perfil de saúde; Odontólogos a Stomatology resident at Federal University of Rio Grande do Sul (UFRGS), Porto Alegre, Rio Grande do Sul State, Brazil

b Professor at Federal University of Santa Maria (UFSM), Stomatology Department, Santa Maria Rio Grande do Sul State, Brazil

c Professor at Federal University of Santa Maria (UFSM), Statistics Department, Santa Maria, Rio Grande do Sul State, Brazil 


\section{INTRODUCTION}

Smoking remains one of the greatest public health concerns worldwide. Currently, there are an estimated 1.3 billion smokers in the world, which represents $29 \%$ of the global population [1]. Almost six million people die from tobacco use every year, both from direct tobacco use and second-hand smoking [3]. Smoking prevalence among Brazilian adults is $17.2 \%$ [3] and the habit is responsible for $13 \%$ of all deaths in this country [4]. Tobacco consumption also produces a significant burden for the economy. A 2010 report showed that R $\$ 20.69$ billion (approximately U\$7 billion) was spent in that year in Brazil to treat tobacco-related diseases, such as cardiovascular and respiratory diseases and some types of cancer [4].

Tobacco contains over 4000 chemicals, of which at least 50 are carcinogenic [2]. It has many harmful effects both on oral and overall health. It is a risk factor for cancer (especially when combined with alcohol consumption), premalignant disorders (such as leukoplakia), periodontal diseases, halitosis, oral candidosis and hairy tongue. Continued smoking is extremely detrimental to the success of periodontal therapy and can be the cause of implant failure [5-8].

To tackle tobacco epidemic, public policies have been created in the past years. For instance, restrictions on tobacco advertisements and public campaigns promoting smoking prevention and cessation. Laws establishing smoke-free environments, including pubs and restaurants, were adopted aiming to protect the population from passive smoking, and to motivate smokers to quit [9]. Increasing cigarette prices is also an effective measure to reduce tobacco use, mainly among adolescents [10].

Offering assistance in quitting is another valuable strategy to control tobacco use. Quit rates are significantly higher when the individual has support [11,12]. The smoking cessation treatment is a cost-effective intervention whose positive outcomes also include the early detection of oral cancer - which is decisive to the success of treatment - and the opportunity to teach patients how to do an oral selfexamination [13]. Identifying the patterns of smoking and the level of nicotine addiction is important to guide strategies for cessation.

Despite the damage caused by smoking, many health professionals do not provide any treatment or information to tobacco users, or even referral into smoking cessation services, in part because of lack of knowledge and skills [14]. Dentists could significantly contribute to tobacco cessation, informing and advising their patients and intervening at individual and community levels [15]. Patients schedule dentist appointments more than once a year, giving an excellent opportunity for dentists to contribute to tobacco prevention and cessation.

The aim of this study was to evaluate the profile of tobacco users, their interest in quitting and dental patients' views about the role of dentists in smoking cessation.

\section{METHODS}

This cross-sectional study was carried out in the Dental School of Federal University of Santa Maria, in Santa Maria, southern Brazil. This project has been approved by the Local Ethical Committee and received a Certificate for Presentation for Ethical Consideration (CAAE) number 12504813.5.0000.5346.

A convenience sample was used with patients from dental clinics who were 18 years of age or older. Data collection occurred between 2013 and 2014, when four researchers interviewed patients of different clinics, including Stomatology, Endodontics, Periodontics, Prosthodontics and General Clinic. Smokers and non-smokers were approached before or after their dental appointment in the waiting room. The researcher assessed eligibility to participate, read a plain language statement describing the project to each potential participant and written informed consent was obtained before proceeding with data collection. Patients were asked to answer a face-to-face interview with twelve closed and open questions aimed at assessing the profile of tobacco users, their interest in quitting smoking and patients' opinions on the role of dentists in smoking cessation. Smokers who answered the first interview were invited to take the Fagerström Test for Nicotine Dependence, a standard test used worldwide to assess nicotine addiction [16].

In order to test reliability and validity of the first questionnaire, a test-retest was done prior to data collection, using the same strategy for applying the questionnaire. Ten percent of the sample was selected and each respondent was asked to complete the questionnaire twice - the second questionnaire was applied a week after the first in order to test the adequacy of the measurement process, its replicability and agreement. The overall agreement of the instrument was measured by the Intraclass Correlation Coefficient (ICC) for discrete variables (smoking time, smoking cessation time, number of cigarettes per day). For binomial categorical variables, Kappa (k) statistic was estimated, and for categorical variables (income and schooling) Weighted Kappa (Kp) was calculated. All of them had had a very good to great replicability. Kuder Richardson reliability coefficient was also calculated, and the result KR-20 $=1$ was obtained.

The statistical analysis was performed with Statistical Package for Social Science (SPSS), version 17. Data was analysed by descriptive statistics and Chi Square test was applied. T-test was used to test the differences among age means. The level of statistical significance was set at $p \leq 0.05$.

\section{RESULTS}

A total of 442 patients answered the first interview assessing the profile of smokers and patients' views about the role of dentists in smoking cessation. The dental school of this study attends around 1,000 patients every year, thus our sample represents $29,4 \%$ of the dental patients of 
the university attended in the period of data collect (three semesters). Among the participants, 146 were men (33\%) and 296 were women (67\%). Ninety-three (93) smokers answered the second interview that assessed their level of nicotine addiction. Demographic results are outlined in Table 1. The mean age was 48.5 years old, and 93 patients $(21.04 \%)$ were smokers, most of them women $(52.7 \%)$. There is a higher frequency of smokers among men (0.001).

A significant association was found between smoking and schooling, as well as between smoking and income. The lower the level of schooling, the higher the frequency of smokers was $(p=0.026)$, and the frequency of nonsmokers was associated with a higher income $(p=0.021)$. Socioeconomics characteristics are shown in Table 2. Among tobacco users, $95.7 \%$ would like to quit smoking and $81.7 \%$ had tried at least once to stop, with an average of 185 days without smoking before relapsing. Only $23.7 \%$ smokers have knowledge of counselling groups for cessation.

Regarding the role of dentists in smoking cessation, 97.8\% of smokers believe that dentists should give information and advice on the damage caused by smoking, but $36.6 \%$ did not receive any orientation from them. The majority of participants of this study $(99.3 \%$ of all participants and $98.9 \%$ of smokers) agree with the law establishing smokefree environments, including pubs and restaurants.

Results from the Fagerström Test for Nicotine Dependence showed that $51.6 \%$ of participants were classified as very low and low dependents, $11.8 \%$ as medium and $36.6 \%$ were classified as high and very high dependents of nicotine. No association was found among the level of dependence and income ( $p=0.883)$, schooling and gender $(p=0.356)$.

Table 1. Description of demographic characteristics of smoker and non-smoker patients in a dental school in Santa Maria, Brazil, 2013/2014

\begin{tabular}{llcccc}
\hline Variable & Category & $\begin{array}{c}\text { Total } \\
(\mathbf{n}=442)\end{array}$ & $\begin{array}{c}\text { Smokers } \\
(\mathbf{n}=93)\end{array}$ & $\begin{array}{c}\text { Non-smokers } \\
(\mathbf{n}=349)\end{array}$ & $p$ \\
Age (Years) & Mean=SD* & $48.5=14.14^{*}$ & $48.09=12.68$ & $48.63=14.43$ & \\
& Minimum & 18 & 19 & 18 & 0.718 \\
& Maximum & 87 & 71 & 87 & \\
Gender & Male & $146(33 \%)$ & $44(47 \%)$ & $102(29.2 \%)$ & 0.001 \\
& Female & $296(67 \%)$ & $49(52 \%)$ & $247(70.8 \%)$ & \\
\hline
\end{tabular}

* Standard Deviation.

Table 2. Description of socioeconomic characteristics of smoker and non-smoker patients in a dental school in Santa Maria, Brazil, $2013 / 2014$.

\begin{tabular}{|c|c|c|c|c|}
\hline Variable & $\begin{array}{c}\text { Total } \\
(n=442)\end{array}$ & $\begin{array}{c}\text { Smokers } \\
(n=93)\end{array}$ & $\begin{array}{c}\text { Non-smokers } \\
\quad(n=349)\end{array}$ & $p$ \\
\hline \multicolumn{5}{|l|}{ Schooling } \\
\hline Incomplete elementary School & $175(39.6 \%)$ & $48(51.6 \%)$ & $127(36.4 \%)$ & \multirow{4}{*}{0.026} \\
\hline Complete elementary School & $96(21.7 \%)$ & $19(20.4 \%)$ & $77(22.1 \%)$ & \\
\hline Complete High School & $127(28.7 \%)$ & $22(23.7 \%)$ & $105(30.1 \%)$ & \\
\hline Undergraduate degree/Postgraduate course & $44(9.9 \%)$ & $4(4.3 \%)$ & $40(11.4 \%)$ & \\
\hline \multicolumn{5}{|l|}{ Occupation } \\
\hline Retired & $68(15.4 \%)$ & $12(12.9 \%)$ & $50(16.6 \%)$ & \multirow{9}{*}{0.479} \\
\hline Student & $25(5.7 \%)$ & $3(3.2 \%)$ & $22(6.3 \%)$ & \\
\hline Technicians & $9(2 \%)$ & $3(3.2 \%)$ & $6(1.7 \%)$ & \\
\hline Administrative professionals & $15(3.4 \%)$ & $2(2.2 \%)$ & $13(3.7 \%)$ & \\
\hline Public administration professionals and businessman & $12(2.7 \%)$ & $2(2.2 \%)$ & $10(2.9 \%)$ & \\
\hline Scientific and intellectual professions Farmer & $10(2.3 \%)$ & - & $10(2.9 \%)$ & \\
\hline Production workers & $28(6.3 \%)$ & $8(8.6 \%)$ & $20(5.7 \%)$ & \\
\hline Sellers and other services/ & $13(2.9 \%)$ & $4(4.3 \%)$ & $9(2.6 \%)$ & \\
\hline Not informed & $262(59.2 \%)$ & $59(63.4 \%)$ & $203(58.1 \%)$ & \\
\hline \multicolumn{5}{|l|}{ Family Income (R\$) } \\
\hline Less than 500 & - & - & - & \multirow{5}{*}{0.021} \\
\hline Between 500 and 1000 & $28(6.3 \%)$ & $6(6.5 \%)$ & $22(6.3 \%)$ & \\
\hline Between 1001 and 2000 & $191(43.2 \%)$ & $53(57 \%)$ & $138(39.5 \%)$ & \\
\hline Between 2001 and 3000/ & $152(34.4 \%)$ & $24(25.7 \%)$ & $128(36.7 \%)$ & \\
\hline More than 3000 & $71(16.1 \%)$ & $10(10.8 \%)$ & $61(17.5 \%)$ & \\
\hline
\end{tabular}


Table 3. Profile of smokers and non-smokers in a dental school in Santa Maria, Brazil, 2013/2014.

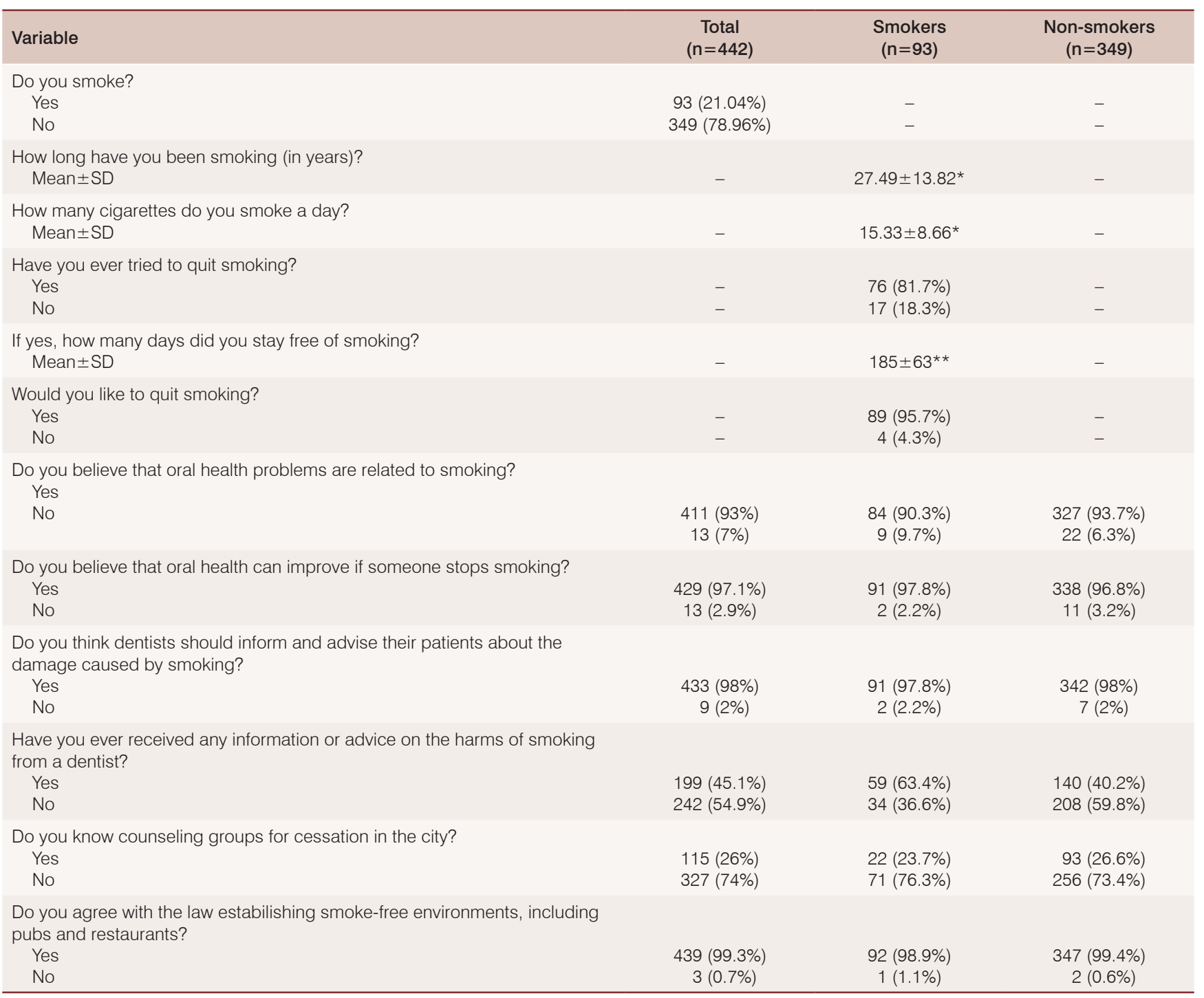

* Standard Deviation. ** Standard Error.

Table 4. Level of nicotine dependence of smokers through Fagerström Test for Nicotine Dependence in a dental school in Santa Maria, Brazil, 2013/2014

\begin{tabular}{lc}
\hline Variable & Smokers $(\mathbf{n}=93)$ \\
$\begin{array}{l}\text { Level of dependence (points) } \\
\text { Mean } \pm \text { SD }\end{array}$ & $10.26 \pm 1.88$ \\
Level of dependence & \\
Very low & $23(24.7 \%)$ \\
Low & $25(26.9 \%)$ \\
Medium & $11(11.8 \%)$ \\
High & $22(23.7 \%)$ \\
Very high & $12(12.9 \%)$ \\
\hline
\end{tabular}

* Standard Deviation.

\section{DISCUSSION}

Identifying the profile of tobacco users and their level of nicotine dependence is essential for planning cessation strategies. The pattern of smoking varies according to country and culture, but previous studies have shown that generally the frequency of smoking is highest amongst people of low income and educational background $[1,17]$, which is consistent with the findings of this current study. The majority of women found in our sample, even among smokers, can be explained by the fact that women are generally more concerned than men about their oral health, and thus, refer more often to dental services. However, smoking was more prevalent in men, which supports the findings of previous studies [17]. Participants of this study had been smoking for 27.49 years in average. Considering that the mean age among smokers was 49.09 years old, the initiation age was low, increasing the concern about tobacco use among adolescents. Smoking is learned and typically initiated during adolescence, creating physiologic and psychological dependence, which interconnect with sociocultural factors [18]. 
The southern region of Brazil has the highest frequency of smokers in the country [3], and this explains the prevalence of smokers in this study, which is higher than the national average. While overall smoking prevalence has fallen in most high-income countries, many low-income countries are still on an upward trend [19]. Moreover, there are substantial inequalities in tobacco use by socioeconomical status [20]. Reducing inequalities in smoking is a key public health priority and tobacco prevention and cessation policies should be focused on this target audience [21]. Among tobacco control interventions, increased tobacco prices may have the potential to reduce health inequalities [20,22]. Also, smokefree policies, smoking curricula in schools and restrictions on marketing opportunities for the tobacco industry can help control tobacco use [19]. Participants of this study, including smokers, have positive attitudes towards the law establishing smoke-free environments, showing that the population is getting more conscious of the damage of active and passive smoking in society.

Findings from our study have shown that the greatest majority of smokers were willing to quit and had attempted at least once to stop smoking, but most of them did not succeed. Besides, a few people were aware of community resources to help them, indicating gaps in advertising counselling groups in the city. A significant number of participants in this study have a high or very high level of nicotine dependence, which indicates they will need counselling and pharmacotherapy to help them quit smoking. Tobacco use cessation therapies, such as individual or group-based counselling [12]' nicotine replacement therapy [23] and other pharmacotherapies [24] can enhance treatment outcomes, improving the odds of quitting, and providing follow-up can produce additional benefit [12]. Adapting interventions to match smokers' needs and expectations may improve treatment outcomes. Health professionals should consider the experiences of smokers in past quit attempts - such as difficulties, side effects of smoking cessation medications - and consider their preferences before recommending a cessation therapy [11].

Dentists are in a unique position to contribute to tobacco control. They have regular contact with patients and can easily identify the impact of tobacco use in the mouth in a routine exam [1]. First of all, dentists have an ethical responsibility to advise all smokers to quit [13]. Moreover, studies have shown that a brief intervention for smoking cessation performed by a dentist will often result in significant health gain, reducing the prevalence of smoking [1]. When oral diseases caused by tobacco are diagnosed, cessation counselling is an essential part of the treatment and cannot be neglected. Although dentists have the opportunity to inform and motivate their patients to stop smoking, this is not a routine in dental care. The findings of this current study are consistent with the findings of previous works $[25,26]$, showing that patients expect dentists to provide information and advice on smoking, but many people did not receive any information about the damage caused by tobacco use. Major barriers identified by dentists to smoking cessation in the dental setting are lack of reimbursement, time constraints, not knowing where to refer, lack of training and knowledge, and not feeling well prepared and confident for doing so [27,29].

Dentists generally have positive attitudes toward the effectiveness of providing tobacco cessation services in the dental settings, thus engaging dental professionals in effective training and providing resources could address a number of the outlined barriers, such as lack of knowledge, training and confidence [28]. The health department of the Brazilian government offers a free training of tobacco cessation for health professionals who work in the public service.

The implementation of tobacco cessation programs into dental universities is another way of involving future dentists in the duty of smoking cessation and there is evidence of the effectiveness of this action $[13,18]$. Generally, dental school curriculum concentrates on tobacco effects in the oral cavity, but does not focus on cessation techniques. Including tobacco cessation treatment programs into dental school curriculum would upgrade dental students to help their patients on quitting attempts and prescribe medications when necessary.

The use of a convenient sample has constrained this current study, since it allows only for an internal validity of results. As with any such research, bias may be present, considering that all participants were patients of a dental service and most of them were positive about the role of dentists in tobacco control. This study raises important questions about characteristics of smokers and the challenge of cessation faced by smokers and health professionals. Further research is required for a clearer understanding of the role of dentists in smoking cessation and prevention, the effectiveness of tobacco control interventions and their effects on social inequalities.

\section{CONCLUSION}

The study had found a higher frequency of smokers among men and an association between smoking and schooling as well as smoking and income. The majority of smokers would like to quit smoking and had tried at least once to stop. The sample believes that dentists should give information and advice about smoking cessation.

\section{REFERENCES}

1. FDI World Dental Federation (FDI), World Health Organization (WHO) Tobacco or oral health: an advocacy guide for oral health professionals. Eddited by Beaglehole RH and Benzian HM; FDI World Dental Federation, Ferney Voltaire, France/World Dental Press, Lowestoft, UK; 2005.

2. WHO. World Health Organization. Global Status Report on noncommunicable diseases 2010. Geneva: World Health Organization; 2011.

3. IBGE. Brazilian Institute of Geografy and Statistics. Nacional Household Sample Survey: Smoking - 2008. Rio de Janeiro: Brazilian Institute of Geografy and Statistics; 2009. Portuguese.

4. ACT +. Alliance for Tobacco Control + Health. Economic losses associated with Tobacco-related diseases for Brazil - Final Report. Rio de Janeiro: Alliance for Tobacco Control + Health; 2011. Portuguese.

5. Reibel J. Tobacco and oral diseases. Update on the evidence, with recommendations. Med Print Pract. 2003;12(1):22-32. https://doi. org/10.1159/000069845 
6. Ferreira Antunes JL, Toporcov TN, Biazevic MGH, Boing AF, Scully C, Petti S. Joint and independent effects of alcohol drinking and tobacco smoking on oral cancer: a large case-control study. PLoS ONE. 2013;8(7):e68132. https://doi.org/10.1371/journal.pone.0068132

7. Busenlechner D, Fürhauser R, Haas R, Watzek G, Mailath G, Pomme B. Long-term implant success at the Academy for Oral Implantology: 8-year follow-up and risk factor analysis. J Periodontal Implant Sci. 2014;44(3):102-8. https://doi.org/10.505/jpis.2014.44.3.102

8. Johnson GK, Slach NA. Impact of tobacco use on periodontal status. J Dent Educ. 2001;65(4):313-21

9. Godoy I. Prevalence of smoking in Brazil: additional measures for smoking control should be a priority in the Year of the Lung. J Bras Pneumol. 2010;36(1):4-5. https://doi.org/10.1590/S1806-37132010000100002

10. Difranza JR, Savageau JA, Fletcher KE. Enforcement of underage sales laws as a predictor of daily smoking among adolescents - a national study. BMC Public Health. 2009;9:107. https://doi.org/10.1186/14712458-9-107

11. Thomas D, Abramson MJ, Bonevski B, Taylor S, Poole SG, Weeks GR, et al. Quitting experiences and preferences for a future quit attempt: a study among inpatient smokers. BMJ Open. 2015;5:e006959. https://doi. org/10.1136/bmjopen-2014-006959

12. Stead LF, Buitrago D, Preciado N, Sanchez G, Hartmann-Boyce J Lancaster $\mathrm{T}$, et al. Physician advice for smoking cessation. Cochrane Database Syst Rev. 2013;(5):CD000165. https://doi.org/10.1002/14651858

13. Maillet JP, Tax CL, Neish NR, Denny AL. Evaluation of Outcomes for Tobacco Cessation Counseling in the Dalhousie University Dental Hygiene Curriculum. J Dent Educ. 2010;74(3):311-7.

14. Selby P, Goncharenko K, Barker M, Fahim M, Timothy V, Dragonetti $\mathrm{R}$, et al. Reviews and Evaluation of Online Dependence Treatment Training Programs for Health Care Practitioners. J Med Internet Res. 2015;17(4):e97. https://doi.org/10.2196/jmir.3284

15. Kalyanpur R, Pushpanjali K, Prasad KV, Chhabra KG. Tobacco cessation in India: A contemporary issue in public health dentistry. Indian J Dent Res. 2012;23(1):123. https://doi.org/10.4103/0970-9290.99061

16. Heatherton TF, Kozlowski LT, Frecker RC, Fagerström K-O. The Fagerström Test for Nicotine Dependence: A revision of the Fagerström Tolerance Questionnaire. Br J Addiction. 1991;86(9):1119-27. https://doi. org/10.1111/j.1360-0443.1991.tb01879.x

17. Li FX, Robson PJ, Ashbury FD, Hatcher J, Bryant HE. Smoking Frequency, Prevalence and Trends, and Their Socio-demographic Associations in Alberta, Canada. Can J Public Health. 2009,100(6):453-8.

18. Christen AG. Tobacco Cessation, the Dental Profession, and the Role of Dental Education. J Dent Educ. 2001;65(4):368-74.
19. Pierce JP, White VM, Emery SL. What public health strategies are needed to reduce smoking initiation? Tob Control. 2012;21:e258-64. https://doi. org/10.1136/tobaccocontrol-2011-050359

20. Hill S, Amos A, Clifford D, Platt S. Impact of tobacco control interventions on socioeconomic inequalities in smoking: review of the evidence. Tob Control. 2014;23:e89-97. https://doi.org/10.1136/tobaccocontrol-2013051110

21. Klumbiene J, Sakyte E, Petkeviciene J, Prattala R, Kunst AE. The effect of tobacco control policies on smoking cessation in relation to gender, age and education in Lithuania, 1994-2010. BMC Public Health. 2015;15:181. https://doi.org/10.1186/s12889-015-1525-8

22. Main C, Thomas S, Ogilvie D, Stirk L, Petticrew M, Whitehead M, et al. Population tobacco control interventions and their effects on social inequalities in smoking: placing an equity lens on existing systematic reviews. BMC Public Health. 2008:8:178. https://doi.org/10.1186/1471 2458-8-178

23. Stead LF, Perera R, Bullen C, Mant D, Hartmann-Boyce J, Cahill K, et al. Nicotine replacement therapy for smoking cessation. Cochrane Database Syst Rev. 2012;(11):CD000146. https://doi.org/10.1002/14651858. CD000146.pub4

24. Cahill K, Stevens S, Perera R, Lancaster T. Pharmacological interventions for smoking cessation: and overview and network meta-analysis. Cochrane Database Syst Rev. 2013;(5):CD009329. https://doi.org/ 10.1002/14651858.CD009329.pub2

25. Walsh MM, Belek M, Prakash P, Grimes B, Heckman B, Kaufman N, et al. The effect of training on the use of tobacco-use cessation guidelines in dental settings. J Am Dent Assoc. 2012;143(6):602-13. https://doi. org/10.14219/jada.archive.2012.0239

26. Kadtane SS, Bhaskar DJ, Agali C, Shah S, Malu A, Jadhav S. Perception about the role of dentists in smoking cessation: a cross-sectional study. Int J Dent Med Res. 2014;1(1):2-7.

27. Prakash P, Belek MG, Grimes B, Silverstein S, Meckstroth R, Heckman B et al. Dentists' attitudes, behaviors and barriers related to tobacco-use cessation in the dental setting. J Public Health Dent. 2013;73:94-102. https://doi.org/10.1111/j.1752-7325.2012.00347.x

28. Ahmady AE, Khoshnevisan MH, Heidari N, Lando HA. Dentist' familiarity with tobacco cessation programs in dental settings in Iran. J Public Health Dent. 2011;71:271-7. https://doi.org/10.1111/1.1752-7325.2011.00262.x 